\title{
STEADFASTNESS OF COLOURS OF OUTDOOR AdVertising Media
}

\author{
Brozovic, M.; MiKota, M. \& PAVlovic, I.
}

Abstract: The paper is based on the research of the colours steadfastness of the outdoor media advertising. Depending on the exposure length of outdoor advertising media, the parameters that enable colour constancy for the specific period of posters exposure to external conditions are investigated. Parameters that influence the steadfastness of colours are: ink type, substrate and exposure time. The stability of colours by using three different types of substrate which are usually used for printing jumbo posters and, properly, the ink on solvent and water base are investigated in the paper. Posters were exposed to external conditions between 15 and 30 days which are the usual periods of exposing. Spectrophotometric method was used for measurement, and the steadfastness of colours is expressed by using the total colour difference $\Delta E_{00}$. The optimal parameters for the realization of jumbo posters depending on the exposure period were determined on the basis of obtained results.

Key words: steadfastness, advertising media, colours, colour difference
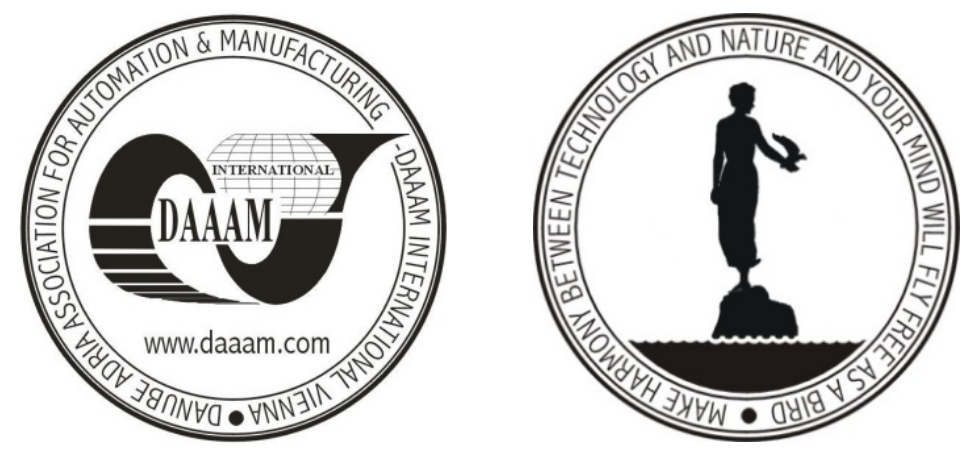

Authors' data: Doc. Dr. Sc. Brozovic, M[aja]; Dr. Sc. Mikota, M[iroslav], Dipl.Ing. Pavlovic, I[vana], Faculty of Graphic Arts, Getaldiceva 2, 10000, Zagreb, Croatia,maja.brozovic@grf.hr, mmikota@grf.hr, ivana.pavlovic@grf.hr

This Publication has to be referred as: Brozovic, M[aja]; Mikota, M[iroslav] \& Pavlovic, I[vana] (2010). Steadfastness of Colours of Outdoor Advertising Media, Chapter, 03 in DAAAM International Scientific Book 2010, pp. 019-026, B. Katalinic (Ed.), Published by DAAAM International, ISBN 978-3-901509-74-2, ISSN 1726-9687, Vienna, Austria

DOI: 10.2507/daaam.scibook.2010.03 


\section{Introduction}

In today's life which is characterized by high mobility of citizens, outdoor advertising, certainly occupies the dominant position in the advertising industry. All available areas, whether they are places for advertising or working areas, become communication channels of advertising industry. This form of advertising can be used independently, as a holder of promotional campaigns, or through the marketing promotion as fulfilment to other media for the purpose of positioning the product or the company on the market. In this way the credibility of the advertised product in the eyes of consumers is possible and the basis for communication with the market through other media is created (Barnard, 2005).

Price of advertising is associated with the period of the time in which posters are published, usually from 15 to 30 days. External media advertising are mainly put in the urban centres or along the high-city and suburban roads, which currently allows the perception of visual messages. Depending on the location in which media is placed advertising communicates with target groups at local, regional or national level.

\section{Problem Approach}

Outdoor media advertising are exposed to the external conditions in a particular period of time in which colour changes occur (Foster, 2008). These changes often manifest as the faded colours. Since outdoor advertising media is used in advertising purposes, constancy of colours as the base holder of the visual messages through the period of exposure is desirable to retain. Colour constancy depends on the parameters used by certain printing technology and they are: type of ink and substrate and time period in which the media is exposed. Since advertising is realized in a defined period of the time, it is necessary to choose parameters that will provide colour constancy in a particular substrate for this period with the lowest possible costs (Mikota et al., 2008). Digital printing is the most commonly used technique for printing of jumbo posters. Printers that use solvent based inks appear on the market in different variants and represent standard within outdoor printers. Printers that use water base inks provide less quality prints compared to the solvent ones, resulting in lower cost realization of the media (Mikota et al., 2008; Kipphan, 2004).

Large format UV printers that enable greater coverage of colour, printing of white and direct printing on different types of materials with UV lamps fixing represent the future of digital printing (Kipphan, 2004, Chakravarty, 2002).

\section{Experimental Part}

As a sample for the colour steadfastness research the poster which presents visual elements that are commonly used in external advertising media (dominant photographs, text and logos of advertisers) is used. Poster also contains a scale of 36 colours used on the poster, which include the fields of CMYK and RGB colours, as well as the fields of grey scale for the measurement analysis. Poster was designed in the A1 format. 
For the experimental part of the work three samples of the poster were printed on three different substrates with different digital printing techniques. Since three different substrates require printing with water or solvent base inks each sample was printed with the digital printing technique which was ideal and the most common for this type of substrate. The first of them is the paper designed for ink jet printing with water base inks, while the other two are for printing with solvent base inks. Selected substrates are the most often used in the printing of outdoor advertising media, and their specifications are as follows:

1) POLYPROP MATT FILM is a long lasting matte coated ink jet polypropylene white film, resistant to tearing, for the internal and external applications. It is cheap alternative to the paper with good, neutral colour properties. It has excellent printing capabilities, it rapidly dries, and colour reproduction is quality with excellent defined edges. It is used for apply on the standing advertisements (Stand building), Pop-up and Roll-up exhibits. It can be used on thermal ink jet printers and piezo ink-jet printers with water base and oil based inks. It comes to offer in different grammages, and for the purposes of this work paper with the weight $170 \mathrm{~g} / \mathrm{m}^{2}$ was used.

2) BLUEBACK PREMIUM SB coating is waterproof billboard paper for high quality indoor and outdoor spacious advertising panels or other poster applications. Its printing side is semi gloss, matte white surface, while on the back is blue painted. It has good moisture resistance and dimensional stability, high resistance to tearing and high opacity even when wet. It is used for applying advertising panels (billboards), for longterm billboards up to three months, as the basis for indoor and outdoor posters, indoor short-term applications, and for long-term outdoor advertising. Regarding the surface coating of the paper, high-quality printing of photographs is remarkable. It is printed on the piezo ink-jet printer with solvent base inks. Print is characterized by high brightness and colour saturation and also with excellent defined edges. It comes to offer in different grammages, and for this paper $135 \mathrm{~g} / \mathrm{m}^{2}$ weight was used.

3) SOLSTAR Satin is a premium coated waterproof outdoor poster / citylight paper for high quality indoor and outdoor poster applications. It is used for solvent based piezo printers. Printing side of the paper is semigloss white surface, while the back side is white. Paper has a good moisture resistance and dimensional stability, high resistance to tearing and high opacity even when wet. Regarding the surface coating of the paper, high-quality printing of photographs is remarkable. Print is characterized by high brightness and colour saturation and excellent defined edges. It is used for application to external and internal billboards, citylight posters, long-term outdoor advertising, and internal short-term applications. For the purposes of this paper the grammage of $160 \mathrm{~g} / \mathrm{m}^{2}$ was used.

For testing the steadfastness of colours three sample posters with the following parameters were used:

1) Poster - printed on POLYPROP MATT FILM with base grammage $170 \mathrm{~g} / \mathrm{m}^{2}$, using water-based ink on the HP Designjet 5000 UV.

2) Poster - printed on BLUEBACK PREMIUM SB (base grammage $135 \mathrm{~g} / \mathrm{m}^{2}$ ) using solvent base inks on the HP Designjet $9000 \mathrm{~s}$.

3) Poster - printed on the surface SOLSTAR Satin (weight $160 \mathrm{~g} / \mathrm{m}^{2}$ ), using solvent base inks on the HP DESIGNJET 5500PS 60 IN. 
On the printed poster samples initial value of the field colour were measured with Spectrolino spectrophotometer. Obtained values of colour are shown in CIE L*a*b* colour system and in Table 1. After that posters were placed in the open position, in the city environment and exposed to weather conditions for 30 days. After 15 days, posters were taken off and the same fields of colour were re-measured. After measuring the posters were again exposed to outdoor weather conditions. After 30 days they were again put off and the same fields of colour were measured under the same conditions. Since the visual observation of colours is very subjective, instrumental colour measurement with spectrophotometric method if an objective assessment of the colour stability, i.e. deviation of each colour after being exposed to weather conditions is necessary. The results of measurements after 15 and 30 days in the form of total colour difference $\Delta \mathrm{E}_{00}$ after 15 and 30 days are presented in the practical part of the paper. (Luo et al., 2001)

\section{Results and Discussion}

The results of testing the steadfastness of colours on the posters under external weather conditions on three different types of papers are shown by the total colour difference $\left(\Delta \mathrm{E}_{00}\right)$ of samples (posters that were exposed to weather conditions) in comparison to the standard (a poster that was not exposed to weather conditions).

\begin{tabular}{|rrrc|rrrr|rrrr|}
\hline & L* & $\mathrm{a}^{*}$ & $\mathrm{~b} *$ & & $\mathrm{~L}^{*}$ & $\mathrm{a}^{*}$ & $\mathrm{~b} *$ & & $\mathrm{~L} *$ & $\mathrm{a}^{*}$ & $\mathrm{~b} *$ \\
\hline A1 & 11.8 & 2.1 & 0.3 & E1 & 54.3 & 0.6 & -2 & $\mathrm{I} 1$ & 77.4 & 0.6 & -1 \\
\hline A2 & 52 & 73.4 & 54 & E2 & 52.4 & 81.5 & -7.4 & I2 & 91 & 1.5 & 18.2 \\
\hline A3 & 85.7 & -19.3 & 62.8 & E3 & 37.4 & -2.5 & -50.4 & I3 & 51.2 & 70.4 & 49.4 \\
\hline B1 & 26.9 & 0.8 & -1.1 & F1 & 62.4 & 0.5 & -2.6 & J1 & 82.4 & 3.5 & -2.5 \\
\hline B2 & 57.3 & -74.7 & 30.3 & F2 & 95 & -6 & 95.5 & J2 & 85.5 & 3.5 & 26 \\
\hline B3 & 64.6 & 42.1 & 61.3 & F3 & 83.5 & -14.5 & -14 & J3 & 88.5 & -7 & 79.4 \\
\hline C1 & 38.2 & 0.4 & -1.5 & G1 & 69.5 & 0.7 & -2.4 & K1 & 92.4 & 0.5 & -1.3 \\
\hline C2 & 25.4 & 25.7 & -55.1 & G2 & 44.5 & 0.3 & 8.4 & K2 & 92 & 0.3 & 17.8 \\
\hline C3 & 51.2 & -28.8 & -32.7 & G3 & 44.3 & 45.5 & -30 & K3 & 65.6 & -35.6 & -34.5 \\
\hline D1 & 4.67 & 0.7 & -2.5 & H1 & 73.2 & 0.4 & -1.4 & L1 & 98 & 0.3 & 0.1 \\
\hline D2 & 62 & -44.9 & -50.4 & H2 & 66 & 1.4 & 24.4 & L2 & 94.3 & 1.2 & 12.3 \\
\hline D3 & 75.3 & -17.7 & 64.3 & H3 & 61.4 & -49.5 & 39.3 & L3 & 35.4 & 15 & -49.3 \\
\hline
\end{tabular}

Tab. 1. Values of colour scale measured after the printing of posters, and prior to exposure to outside conditions as a standard for the needs of instrumental measurements

Table 1 shows values of colour scale measured after the printing of posters, and prior to exposure to outside conditions as a standard for the needs of instrumental measurements. 
Colour changes that occurred after 15 and 30 days, are shown in the histogram in Figures 1, 2 and 3 with respect to the types of paper. $\mathrm{X}$ axis shows specified colours that were measured (Table 1), and the y axis has values of total colour difference $\Delta \mathrm{E}_{00}$. Since the value $\Delta \mathrm{E}_{00} \leq 3.0$ is limit for visual acceptability of colours, values above the limits present visually obvious deviations of colours on prints from the standards. Below the limit colour changes that occurred were visually acceptable, that is, the human eye doesn't see the difference between them.

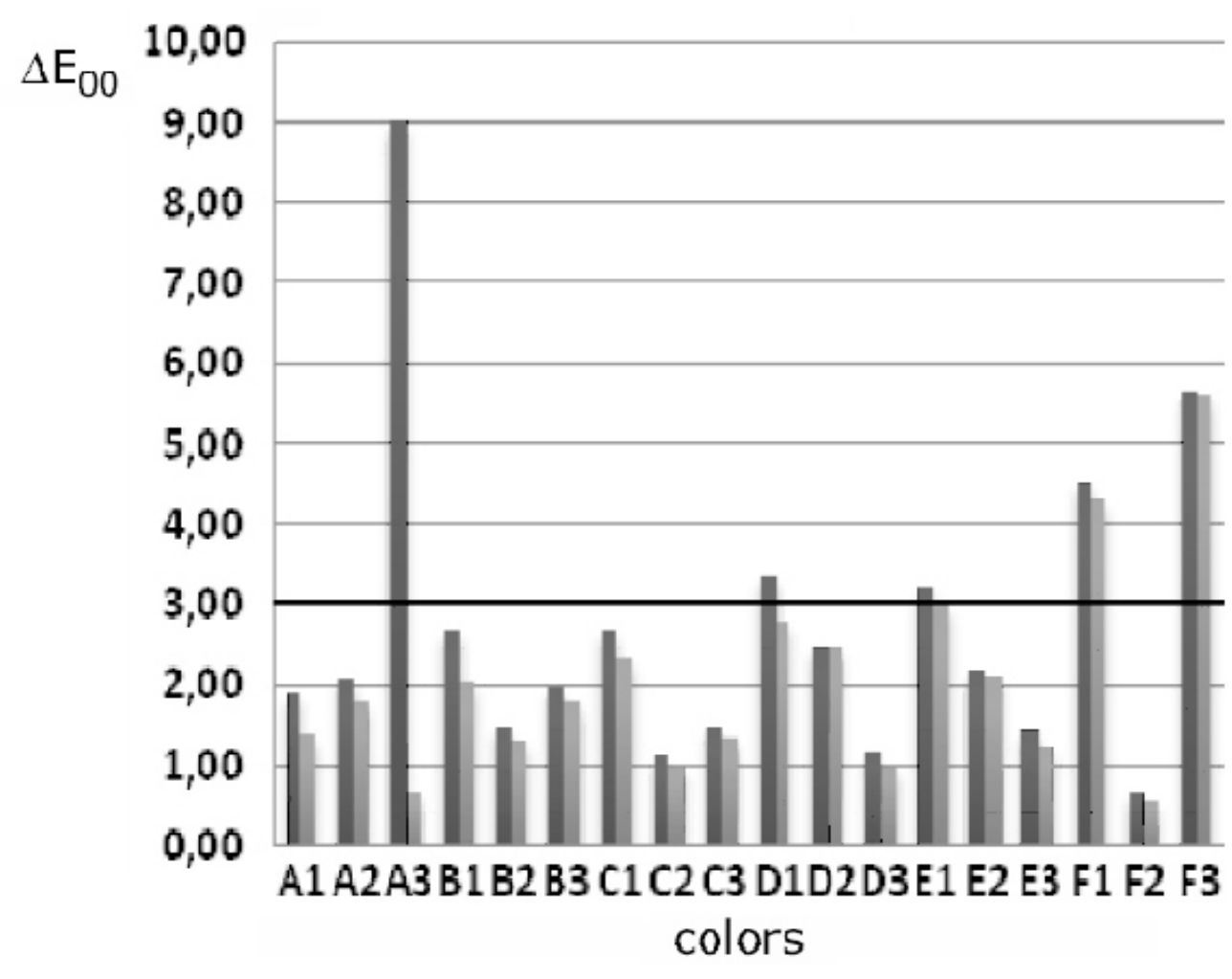

15 days

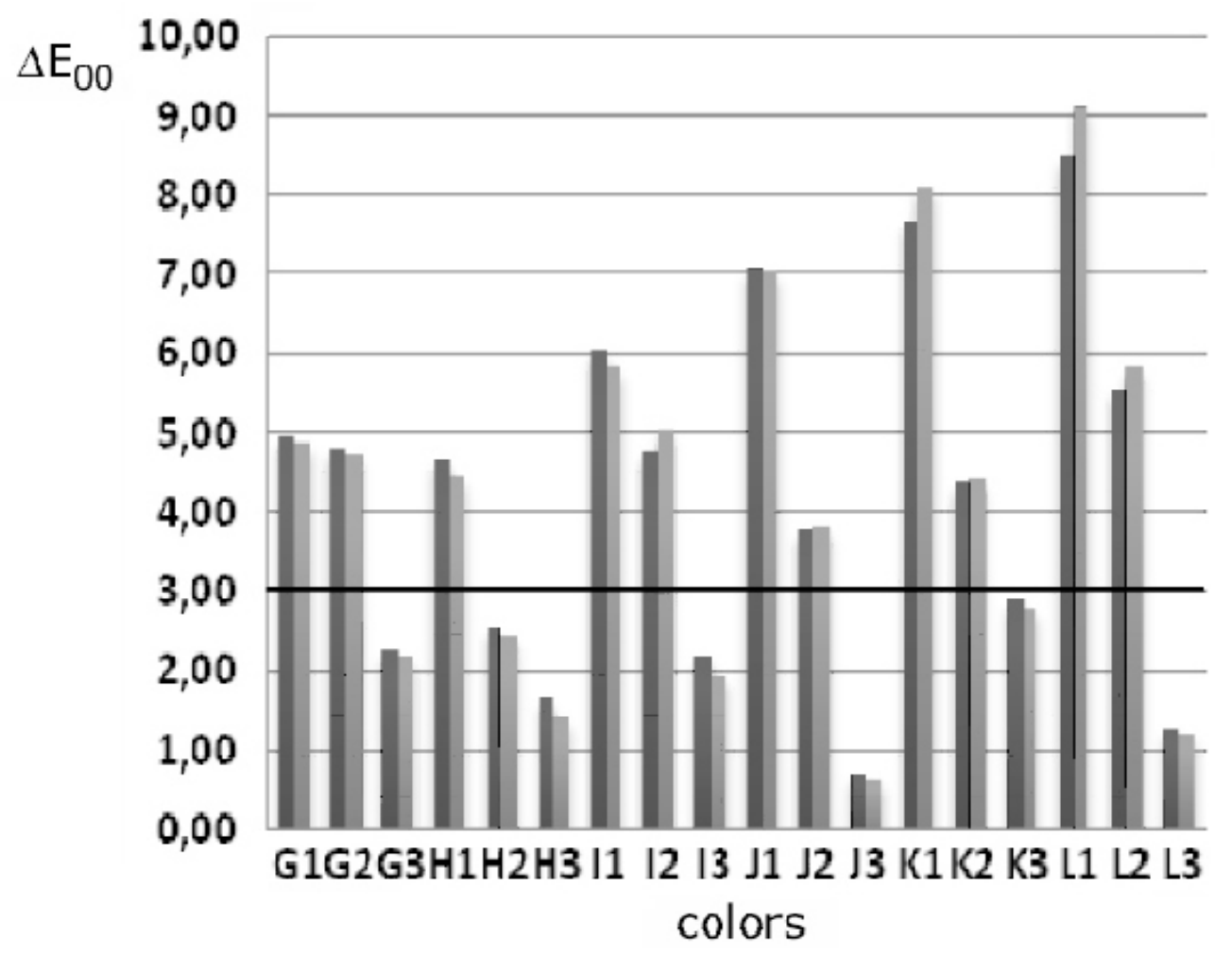

30 days

Fig. 1. Colour changes after 15 and 30 days on Matt Polyprop film surface 

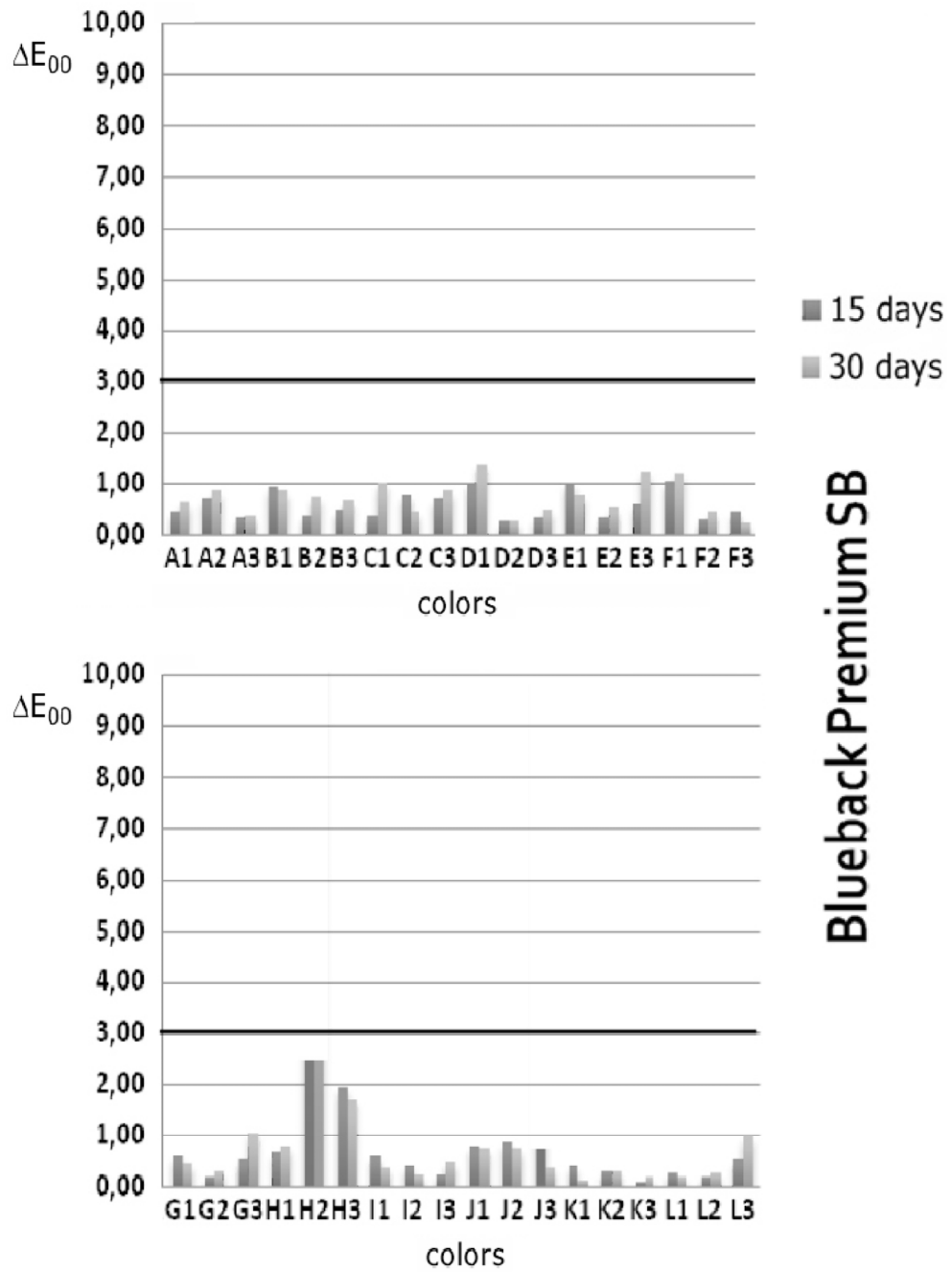

Fig. 2. Colour changes after 15 and 30 days on Blueback Premium SB base 


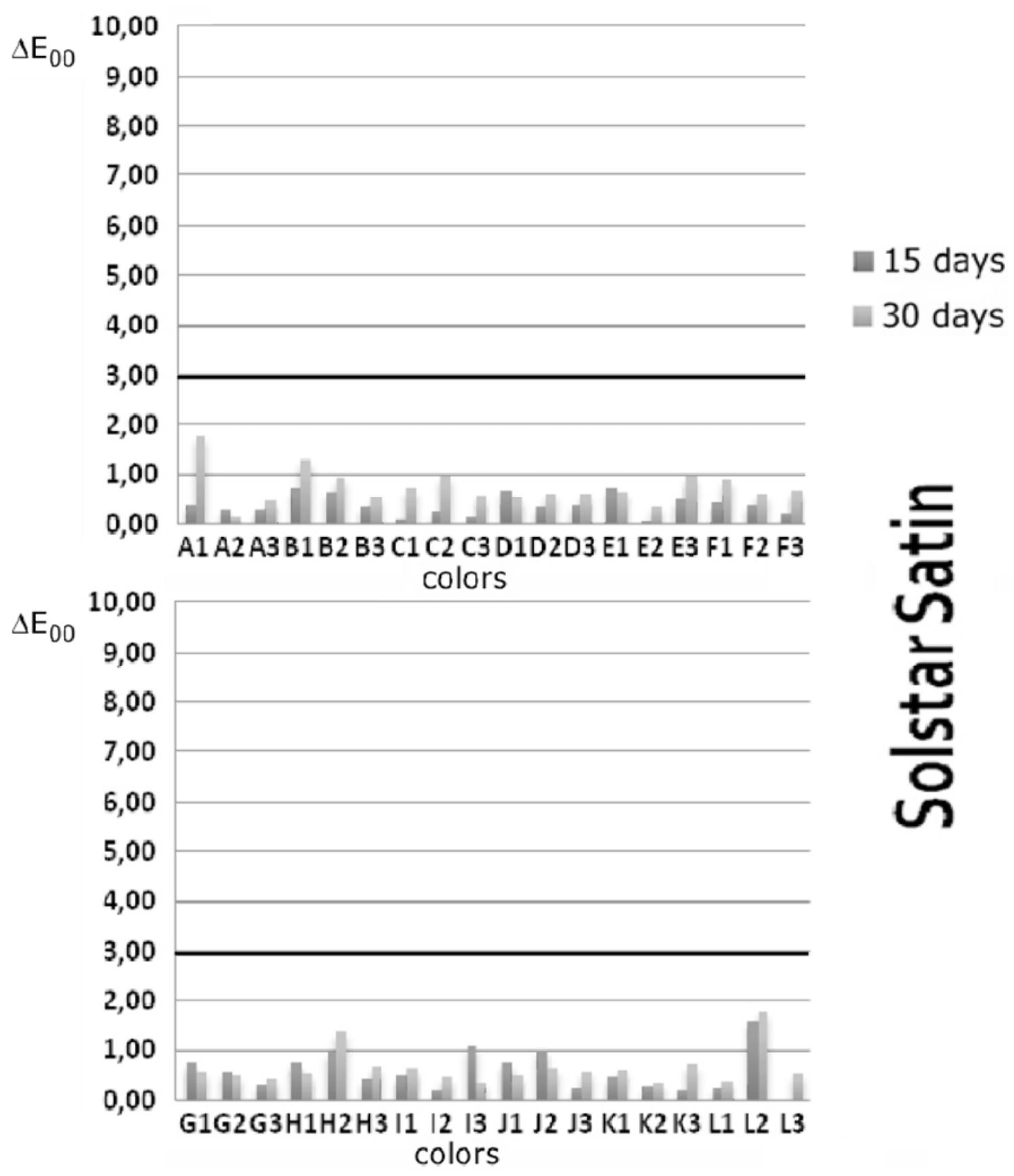

Fig. 3. Colour changes after 15 and 30 days on the Solstar Satin surface

From the comparison of histograms 1, 2 and 3 is visible that a poster printed on POLYPROP MATT surface shows the greatest colour change on all 36 fields of colour. $\Delta \mathrm{E}_{00}$ shows the most visible colour differences of exposed posters in relation to the standard. Posters printed on BLUEBACK PREMIUM SB and SOLSTAR Satin substrates, show very small deviations of colours as the most values of colour changes are below or exactly $2.0\left(\Delta \mathrm{E}_{00} \leq 2.0\right)$. Results analysis according to the deviations of each colour indicates that the full tone basic colours, such as colours: A2, B2, C2, D2, E2 and F2 show the visual acceptability to all three types of paper. Looking at colours of gray scale (A1, B1, C1, E1, F1, G1, H1, I1, J1, K1, L1), it is clear that when using Matt Polyprop film substrate visible changes with change of 
colour brightness occurred. From the $1^{\text {st }}$ histogram is visible that with increasing values of brightness leads to greater colour deviations. Colour with maximum brightness K1 together with white colour (the colour of paper) shows unacceptable deviation, while colours with the small brightness values (A1, B1, C1 and D1) show acceptable reproduction $\left(\Delta \mathrm{E}_{00} \leq 3.0\right)$. Other colours with greater brightness values G2, I2, J2, K2, and L2) also show significant deviations. Given the length of exposure to external conditions, from the $1^{\text {st }}$ histogram it is evident that colour changes after 15 days exposure are greater than after 30 days. From the $2^{\text {nd }}$ and $3^{\text {rd }}$ histogram is evident that the most colour changes occurred after 30 days of exposure.

\section{Conclusion}

The aim of the paper was to identify which of the parameters used by the printing technology is optimal for outdoor media advertising. For the paper three types of substrates, two types of inks and different period of time exposure of posters to weather conditions were used. Based on the research results it can be concluded that the greatest influence on the steadfastness of colours has a type of ink. This is evident from the results obtained and shown on the $2^{\text {nd }}$ and $3^{\text {rd }}$ histogram. It is also concluded that the brightness of colours has the greatest influence on the sensation of the steadfastness. Based on the obtained results, it is clear that colours with the less brightness values show small deviations, i.e. visually acceptable deviations regardless of the ink type and substrate. At colours with higher brightness values, variations significantly depend on the type of used inks. Parameter that least affects the colour steadfastness in real time is the time of the exposure of posters to external conditions. Deviations exist, but they are at least visible in all studied parameters. Given the foregoing, it can be concluded that, for the design of posters, it is necessary to use fields of full colours with less value of brightness to obtain the reproduction of colours that will maintain its steadfastness in the above exposure period regardless of the used inks and substrates for printing.

\section{References}

Barnard, M. (2005). Graphic Design as Communication, Routledge, ISBN: 0-41527813-9, Great Britain

Chakravarty, B. (2002). Digital Colour Printing Technology, Asian Books Pvt Ltd, ISBN: 8186299211, New Delhi

Foster J. (2008). Poster Design for the Next Century, Rockport Publishers, ISBN: 1592534341, USA

Kipphan, H. (2004). Handbook of Print Media, Springer Verlag Berlin, ISBN 3-54067326-1, Germany

Luo, M. R.; Cui, G. \& Rigg, B. (2001)., The Developement of the CIE Color Formula, Color Research \& Application, Vol. 26, No. 5 (Aug. 2001) 340 - 350, ISSN: 0361-2317

Mikota, M.; Brozovic, M. \& Pavlovic, I. (2008). Quality of the photo presentation of fashion novelties in the media of out-of-home advertising. Journal of Textile and Clothing Technology, Vol. 57, No. 9 (9, 2008), 457 - 464, ISSN 0492-5882 